\section{Kidney \\ Blood Pressure Research}

Kidney Blood Press Res 2014;39:490-496

DOI: 10.1159/000368459

Published onlıne: November 23, 2014

Accepted: September 15, 2014

\title{
Hemodynamic Behavior During Hemo- dialysis: Effects of Dialysate Concentrations of Bicarbonate and Potassium
}

\author{
Bruno C. Silva ${ }^{a}$ Geraldo R.R. Freitas ${ }^{a}$ Vitor B. Silva ${ }^{a}$ Hugo Abensur ${ }^{a}$ \\ Claudio Luders ${ }^{a}$ Benedito J. Pereira ${ }^{a}$ Rodrigo B. de Oliveira ${ }^{a}$ \\ Manuel C.M. Castro ${ }^{a}$ Rosa M.A. Moysés ${ }^{a, b} \quad$ Rosilene M. Elias
}

aNephrology Division, University of São Paulo, School of Medicine; ' ${ }^{\text {a }}$ Medicine Master Degree Program, Universidade Nove de Julho (UNINOVE), São Paulo, Brazil

\section{Key Words}

Hemodialysis - Bicarbonate - Potassium - Hemodynamic - Peripheral arterial resistance • Dialysate

\begin{abstract}
Background/Aims: Ultrafiltration that occurs during hemodialysis (HD) promotes profound alterations in a relatively short period of time. The dialysate content of bicarbonate (DBic) and potassium (DK) may have impact over intradialytic hemodynamics, which goes beyond ultrafiltration, and its impact was evaluated in a prospective cohort. Methods: 30 patients under $\mathrm{HD}$ were submitted to hemodynamic assessment $(\mathrm{HA})$ at the beginning and at the end of HD sessions, through a non-invasive method. Serum minus dialysate potassium concentration was expressed as K-Gap. Cardiac index (CI) and peripheral arterial resistance (PAR) variation (post-HD minus pre-HD) were expressed as $\triangle \mathrm{CI}$ and $\triangle \mathrm{PAR}$. Dialysate content of sodium and calcium were expressed as DNa and DCa, respectively. Results: Mean DNa, DK and DBic were, respectively, $136.4 \pm 1.1,2.1 \pm 0.6$ and $38.2 \pm 2.1 \mathrm{mEq} / \mathrm{L}$. In 15 patients, DCa was $>1.5 \mathrm{mmol} / \mathrm{L}$ and in the other 15 patients $\leq 1.5 \mathrm{mmol} / \mathrm{L}$. The K-Gap ranged from 1.4 to $5.1 \mathrm{mEq} / \mathrm{l}$ (median $3.0 \mathrm{mEq} / \mathrm{L})$. There was a reduction in post-HD CI and systolic blood pressure $(\Delta \mathrm{CI}=-0.72 \mathrm{l} / \mathrm{min} /$ $\mathrm{m}^{2}$ and $-11.3 \pm 15.1 \mathrm{mmHg}$, respectively, $\mathrm{p}<0.001$ for both). Conversely, PAR increased ( $\triangle P A R$ $\left.=272 \mathrm{dyn} . \mathrm{s} / \mathrm{cm}^{5}, p<0.001\right)$. Lower post-HD CI was was associated to higher DBic $(p=0.0013)$ and lower K-Gap $(p=0.026)$. In multivariate analysis, $\triangle \mathrm{CI}$ was dependent on DBic and K-Gap, whereas $\triangle$ PAR was dependent on dialysate calcium during HD. Conclusion: We confirmed that $\mathrm{Na}$ and $\mathrm{Ca}$ dialysate content exerts and important role on hemodynamic during HD. In addition, our findings pointed out that higher dialysate concentrations of bicarbonate and potassium promote lower cardiac performance at the end of hemodialysis session.
\end{abstract}




\section{Kidney \\ Blood Pressure Research}

Kidney Blood Press Res 2014;39:490-496

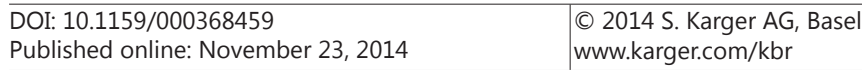

Silva et al.: Hemodynamic Behavior in Hemodialysis: Dialysate Bicarbonate and Potassium Content

\section{Introduction}

Not only traditional cardiovascular (CV) risk factors, but also bone mineral disorders and chronic volume overload play major role in the high mortality observed in chronic kidney disease (CKD) population [1-3]. Individualized hemodialysis (HD) is prescribed by nephrologists in order to keep CKD patients close to optimal physiologic conditions, through reaching dry weight and keeping serum electrolytes, hemoglobin and bicarbonate concentrations within a normal range. Notably, volume overload leads heart and vascular bed to a stressful hemodynamic condition, in which both are submitted to an overfilling state during the interdialytic interval, while ultrafiltration (UF) during HD treatment promotes rapid volume removal. (2) This process may be accompanied by significant intradialytic hypotension and possibly, transient myocardial ischemia, which may impair left ventricular (LV) function even after restoration of myocardial blood flow, a phenomena known as myocardial stunning (MS), which is a cause of chronic LV dysfunction [4].

In maintenance HD treatment, dialysate prescription could exert significant impact over hemodynamic stability during the UF process [5-7]. It is already known that higher dialysate concentrations of sodium and calcium promote better UF tolerability, with lower hypotensive episodes during HD [8]. Nevertheless the role of other electrolytes on intradialytic hemodynamics remains subject of debate.

Individualizing dialysate content of bicarbonate and potassium may bring serum concentrations of these electrolytes close to normal range. Nevertheless, the impact of such prescription on intradialytic hemodynamics remains unknown. Therefore, the aim of the present study was to investigate, through a non-invasive methodology, the impact of dialysate content of bicarbonate and potassium on hemodynamic changes during HD treatment.

\section{Patients and Methods}

\section{Study population}

Adult patients receiving HD for at least 6 months were prospectively enrolled in this observational study. Patients with diabetes mellitus, non-sinusal cardiac rhythm, recent parathyroidectomy (less than 6 months), and prior history of congestive heart failure were excluded.

\section{Study protocol}

The study was performed according to the guidelines of the Helsinki Declaration and was approved by the Research Ethics Boards of the Universidade de São Paulo (CAPPesq \#235.350). All subjects provided written informed consent before participation.

During the study, there was no change in dialysate content of sodium (DNa), potassium (DK), calcium (DCa), glucose and bicarbonate (DBic).

All HD sessions were performed using Fresenius 4008S machines and high flux polysulfone membranes (Fresenius Medical Care ${ }^{\mathrm{Tm}}$, Bad Homburg, Germany). Blood flow was set to $350 \mathrm{ml} / \mathrm{minute}$ and dialysate flow to $800 \mathrm{ml} / \mathrm{min}$ in all patients.

\section{Laboratory Values}

Blood tests were performed before and after each dialysis session. Biochemical concentrations of serum $\mathrm{Ca}, \mathrm{P}, \mathrm{Na}, \mathrm{K}$, creatinine, albumin and hemoglobin were measured. Serum intact parathyroid hormone (PTH) levels were measured using a chemiluminescence assay $(\mathrm{RR}=15-65 \mathrm{pg} / \mathrm{ml})$. HD adequacy was assessed by monthly Kt/V measurements using the Daugirdas' equation [9]. Additionally, the difference between serum and dialysate concentration of bicarbonate, potassium and sodium were calculated and named as Bic-Gap, K-Gap and Na-Gap, respectively.

\section{Hemodynamic measurements}

Cardiac output index (CI), stroke volume (SV - integrated mean of the flow waveform between the current upstroke and the dichotic notch), peripheral arterial resistance (PAR - ratio of mean arterial pressure to stroke volume multiplied by heart rate) and blood pressure (BP) were accessed by finger beat- 


\section{Kidney Blood Pressure Research}

to-beat monitor Finometer ${ }^{\circledR}$ (Finapress Medical Systems BV, Arnhem, The Netherlands) within 15 minutes after starting HD session (predialysis) and again, 15 minutes before its end (post-dialysis). If frequent extra systoles were observed, monitoring was interrupted and the entire protocol was repeated afterwards. Ectopic beats were excluded from analysis. Differences between postand pre-HD CI and PAR were expressed as $\triangle \mathrm{CI}$ and $\triangle \mathrm{PAR}$, respectively.

\section{Kidney Blood Press Res 2014;39:490-496}

DOI: $10.1159 / 000368459$

Publisned onIIne: November 23, 2014

(C) 2014 S. Karger AG, Basel

www.karger.com/kbr

Silva et al.: Hemodynamic Behavior in Hemodialysis: Dialysate Bicarbonate and Potassium Content

Table1. Baseline characteristics of the studied population. $(\mathrm{N}=30)$

\begin{tabular}{lcc}
\hline Variable & Mean \pm SD or $\%$ & Median $\left(25^{\text {th }}, 75^{\text {th }}\right)$ \\
\hline Age (years) & $39.6 \pm 11.3$ & $28(31,50)$ \\
Male Sex, \% & 57 & \\
Dialysis vintage (months) & $166 \pm 108$ & $176(33.5,245.0)$ \\
Body surface area (Kg/m $\left.{ }^{2}\right)$ & $1.72 \pm 0.3$ & $1.72(1.57,1.91)$ \\
Hypertensive subjects (\%) & 60 & \\
Hemoglobin (g/dl) & $11.5 \pm 1.8$ & $11.1(10.3,13.2)$ \\
PTH (pg/ml) & $481 \pm 373$ & $524(182,663)$ \\
Standard Kt/V & $2.54 \pm 0.93$ & $2.43(2.16,2.71)$ \\
Ultrafiltration (ml/Kg/h) & $11.2 \pm 4.4$ & $11.41(8.49,14.87)$ \\
Serum albumin (g/dL) & $4.0 \pm 0.3$ & $4.0(3.9,4.3)$ \\
Erythropoietin dose (U.I./Kg/week) & $121.4 \pm 114.1$ & $74.7(27.8,203,7)$ \\
\hline PTH, parathyroid hormone; Data are presented as mean \pm SD or median and \\
interquartile (25, 75), unless indicated otherwise.
\end{tabular}

\section{Statistical analyses}

Categorical variables were presented as proportion, and continuous variables were presented as mean \pm SD unless indicated otherwise. Differences between continuous variables were calculated using Student $t$ test or Mann-Whitney $U$ test as appropriate. The $\chi^{2}$ or Fisher's exact test was used to compare categorical variables. Paired $t$ test or Wilcoxon matched-pairs were used to compare variables pre- and post-hemodialysis, as appropriate. Relationships between single variables were examined by Spearman correlation coefficient. Multivariable relationships between $\Delta \mathrm{CI}$ and independent variables, and between $\triangle \mathrm{PAR}$ and independent variables were also examined by stepwise linear regression, with $\mathrm{P}<0.05$ to enter and $P>0.1$ to remove. A two-tailed $P$ value $<0.05$ was considered significant. Analyses were performed with SPSS 21.0.1 (SPSS Inc., Chicago, USA) and GrapPad Prism 6 software (San Diego, USA).

\section{Results}

\section{Baseline characteristics}

As shown in Table 1, our population $(\mathrm{N}=30)$ was relatively young, and with a high dialysis vintage. Sixty percent of them had arterial hypertension and also were taking hypotensive drugs. The dialysis dose (measured by standard Kt/V), serum albumin and hemoglobin levels were within recommended targets. The ultrafiltration rate was high.

\section{Dialysate prescription}

Mean DNa, DK and DBic were, respectively, $136.4 \pm 1.1,2.1 \pm 0.6$ and $38.2 \pm 2.1 \mathrm{mEq} / \mathrm{L}$. In 15 patients, DCa was $>1.5 \mathrm{mmol} / \mathrm{L}$ and in the other 15 patients $\leq 1.5 \mathrm{mmol} / \mathrm{L}$. The K-Gap ranged from 1.4 to $5.1 \mathrm{mEq} / \mathrm{l}$ (median $3.0 \mathrm{mEq} / \mathrm{L}$ ) and the Bic-Gap ranged from -24 to -8.7 $\mathrm{mE} / \mathrm{L}$ (median $-17.8 \mathrm{mEq} / \mathrm{L}$ ).

Biochemical and hemodynamic variations secondary to HD treatment

Extracellular fluid removal secondary to ultrafiltration caused an expected reduction in SV and CI and a compensatory PAR increase. All but three patients decreased post-HD CI. From pre- to post-HD, mean CI drop was $-0.72 \mathrm{l} / \mathrm{min} / \mathrm{m}^{2}$ (range: -2.68 to $0.44 \mathrm{l} / \mathrm{min}$ / $\mathrm{m}^{2}$ ). Conversely, PAR increased in all but five patients (mean increase: $272 \mathrm{dyn} . \mathrm{s} / \mathrm{cm}^{5}$, range: -522 to 2,231 dyn.s $/ \mathrm{cm}^{5}$ ). Systolic BP was significantly reduced (from $133.2 \pm 23.8$ to 121.9 $\pm 25.4 \mathrm{mmHg}, \mathrm{p}=0.0003$ ), which was not observed for diastolic BP (from $74.5 \pm 12.2$ to 74.5 $\pm 13.6 \mathrm{mmHg}, \mathrm{p}=0.990$ ). All these significant hemodynamic changes are shown in Figure 1. Diffusive process promoted an increase in serum bicarbonate (from $20.7 \pm 3.4$ to $29.6 \pm 3.3$ $\mathrm{mEq} / \mathrm{L}, \mathrm{p}<0.0001$ ) and a decrease in serum potassium (from $5.2 \pm 0.5$ to $3.8 \pm 0.5 \mathrm{mEq} / \mathrm{l}$, $\mathrm{p}<0.0001$ ). 


\section{Kidney \\ Blood Pressure Research}

\section{Kidney Blood Press Res 2014;39:490-496}

DOI: 10.1159/000368459

Publisned onlIne: November 23, 2014

(c) 2014 S. Karger AG, Basel

www.karger.com/kbr

Silva et al.: Hemodynamic Behavior in Hemodialysis: Dialysate Bicarbonate and Potassium Content

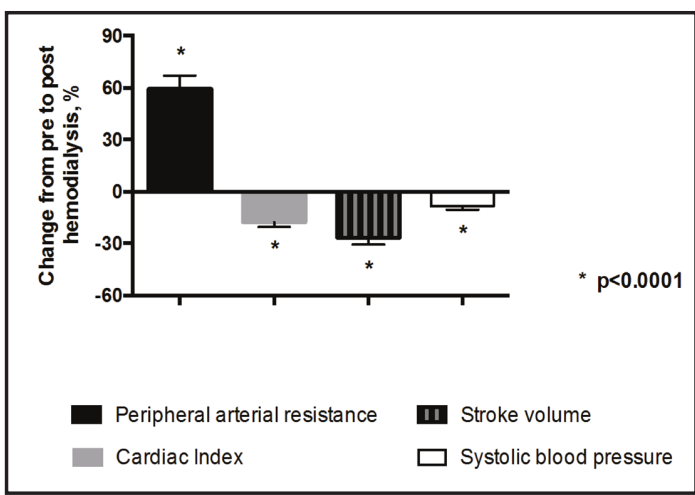

Fig. 1. Changes from pre- to post- hemodialysis hemodynamics, expressed as $\%$ of change \pm SEM. There was a significant decrease in cardiac index and in stroke volume, and peripheral arterial resistance increase.

Factors related to $\triangle C I$ and $\triangle P A R$ behaviour during hemodialysis sessions

a) Sodium and potassium Gap and its respective dialysate concentrations.Variables that correlated to a higher CI drop were: lower K-Gap $(\mathrm{r}=0.405, \mathrm{p}=0.026)$, lower serum $\mathrm{K}$ levels ( $r=0.430, p=0.018)$, higher DBic levels $(\mathrm{r}=-0.447, \mathrm{p}=0.001)$, higher serum Na levels $(\mathrm{r}=-0.417, \mathrm{p}=0.022)$, and higher Na-Gap $(\mathrm{r}=-0.405, \mathrm{p}=0.026)$. The relationships between $\Delta \mathrm{CI}$ and $\mathrm{Na}-$ and $\mathrm{K}$-Gap are better illustrated in Figure 2. No correlation was found between $\triangle \mathrm{PAR}$ and any biochemical tested variables.

b) Bicarbonate dialysate content. DBic was categorized as low $(<38 \mathrm{mEq} / \mathrm{L})$ or high DBic ( $>38 \mathrm{mEq} / \mathrm{L})$, according to its median, as shown in Table 2. Patients dialyzed with higher DBic presented a higher post-HD CI drop $\left(-0.92 \pm 0.59 v s .-0.09 \pm 0.47 \mathrm{l} / \mathrm{min} / \mathrm{m}^{2}\right.$, $\mathrm{p}=0.002)$. There was no difference in $\triangle \mathrm{PAR}$ and UF rate.

A multivariable analysis was done to elucidate factors related to $\triangle \mathrm{CI}$ and $\Delta \mathrm{PAR}$ as a consequence of HD treatment, in which all significant biochemical variables and dialysate content profile were modeled together, adjusted to UF rate. All models are seen in Table 3. $\Delta \mathrm{CI}$ was independently related to DBic and K-Gap, which accounted for $51.2 \%$ of its variation during HD. Higher DBic ( $>38 \mathrm{mEq} / \mathrm{L}$ ) and lower K-Gap were associated to lower post-HD CI. $\triangle$ PAR was independently related to DCa, which explained $31.9 \%$ of its variation during HD.

\section{Discussion}

In this study, we found that $\Delta \mathrm{CI}$ is strongly dependent on dialysate concentrations of bicarbonate and potassium. Lower post-HD CI (higher drop) was associated to higher DBic and lower K-Gap.
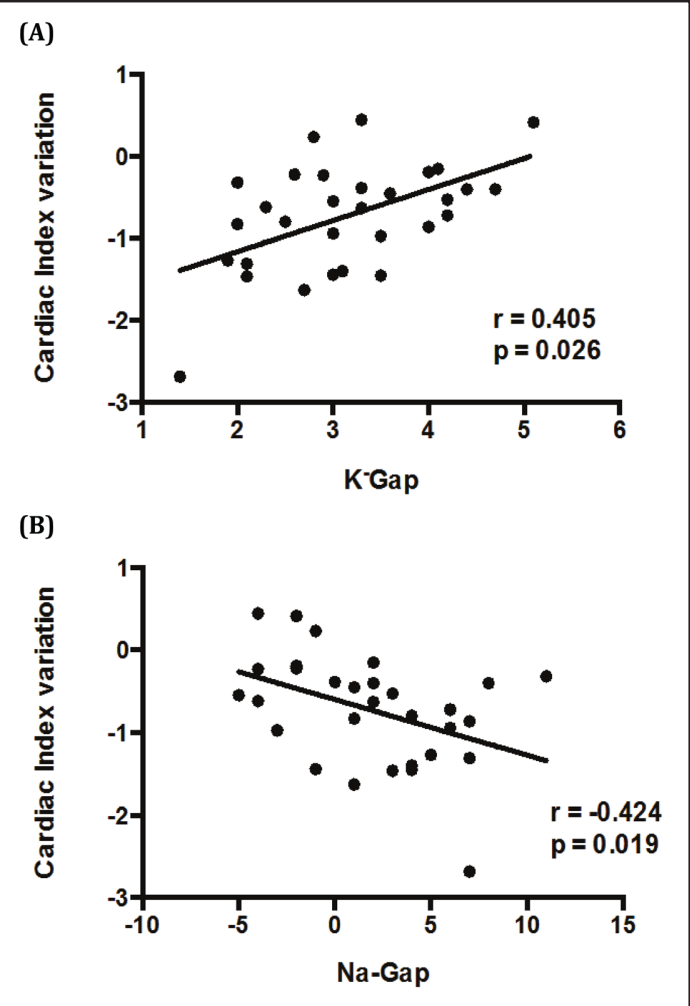

Fig. 2. Spearman correlations between cardiac index variation $(\Delta \mathrm{CI})$ and $\mathrm{K}-\mathrm{Gap}(\mathrm{A})$, and Na-Gap (B). (A). Lower the K-Gap, higher the CI drop. This can be concentration. (B). Higher Na-Gap (towards posiare more likely to have negative $\mathrm{Na}$ balance during HD. On the opposite way, lower Na-GAP (towards negative values) leads to lower post-HD CI drop. These patients are more likely to develop positive Na balance during HD. a consequence of higher pre-HD serum $\mathrm{K}$ or a lower 


\section{Kidney Bloód Pressure Research}

Hemodynamic changes during hemodialysis

Ultrafiltration, a

process that removes intravascular volume, promotes a controlled hypovolemic state during HD sessions. In this study, fluid removal led to stroke volume reduction, with consequent $\mathrm{CI}$ decrease, while PAR increased, with little changes in BP. These same hemodynamic findings were obtained by Riddez et al [10], in a study that performed a venosection of $900 \mathrm{ml}$ in healthy individuals under invasive hemodynamic monitoring. However, HD is a much more complex procedure, in which serum electrolytes and osmolarity change throughout its duration, according to a myriad of factors, such as patients' clinical characteristics, HD efficiency and dialysate prescription, which also influence hemodynamic response to the induced hypovolemia.

\begin{tabular}{l|l|}
\hline Kidney Blood Press Res 2014;39:490-496 \\
\hline DOI: 10.1159/000368459 & (c) 2014 S. Karger AG, Basel \\
Publisned onmlne: November 23, 2014 & wwrger.com/kbr \\
\hline
\end{tabular}

Silva et al.: Hemodynamic Behavior in Hemodialysis: Dialysate Bicarbonate and Potassium Content

Table 2. Baseline clinical, laboratorial, hemodynamic and dialysate content characteristics, according to higher or lower than median DBic content

\begin{tabular}{lccc}
\hline & $\begin{array}{c}\text { DBic } \leq 38 \mathrm{mEq} / \mathrm{l} \\
(\mathrm{n}=16)\end{array}$ & $\begin{array}{c}\text { DBic }>38 \mathrm{mEq} / \mathrm{l} \\
(\mathrm{N}=14)\end{array}$ & $\mathrm{p}$ \\
\hline Men (\%) & 62 & 50 & 0.71 \\
Age (years) & $37.1 \pm 11.3$ & $42.6 \pm 11.1$ & 0.19 \\
Dialysis Vintage (months) & $185 \pm 112$ & $140 \pm 105$ & 0.38 \\
Ejection Fraction (\%) & $65.4 \pm 4.3$ & $63.4 \pm 6.0$ & 0.38 \\
LVMI (g/m ${ }^{2}$ ) & $103(75,132)$ & $107(71,126)$ & 0.91 \\
ACEI/ARB (\%) & 31.2 & 28.6 & 1 \\
$\beta$ blockers (\%) & 25 & 43 & 0.44 \\
Ca chanel blockers (\%) & 25.0 & 18.7 & 1 \\
DCa (mEq/L) & $3(3,3.5)$ & $3.5(3,3.5)$ & 0.08 \\
DK (mEq/L) & $2.1 \pm 0.5$ & $2.0 \pm 0.7$ & 0.79 \\
DNa (mEq/L) & $136.6 \pm 1.1$ & $136.1 \pm 1.0$ & 0.24 \\
Na (mEq/L) & $137.3 \pm 4.0$ & $139.4 \pm 3.7$ & 0.15 \\
K (mEq/L) & $5.3 \pm 0.5$ & $5.1 \pm 0.5$ & 0.36 \\
Bicarbonate (mEq/L) & $21.25(18.8,22)$ & $20.4(18.9,22.4)$ & 1 \\
Hb (g/dL) & $11.45 \pm 1.5$ & $11.65 \pm 2.1$ & 0.77 \\
Ionized Ca (mEq/L) & $4.7 \pm 0.5$ & $4.8 \pm 0.4$ & 0.55 \\
Baseline CI (L/min/m ${ }^{2}$ ) & $3.9(3.2,5.5)$ & $3.7(2.9,4.4)$ & 0.54 \\
Baseline PAR (dyn.s/cm 5 ) & $1215 \pm 456$ & $1347 \pm 406$ & 0.42 \\
\hline LVMI: left ventricular mass index, ACEI: angiotensin conversor enzyme inhibitor, ARB: \\
angiotensin receptor blocker, DCa: dialysate content or Calcium, DK: dialysate content of \\
potassium, DNa: dialysate content of sodium, Hb: hemoglobin, CI: cardiac index, PAR: \\
peripheral arterial resistance. & & & \\
\hline
\end{tabular}

Table 3. Stepwise multiple linear regression analysis between the delta in cardiac index $(\Delta \mathrm{CI})$ and the delta in peripheral arterial resistance $(\triangle \mathrm{PAR})$ and independent variables

\begin{tabular}{|c|c|c|c|}
\hline Independent Variable & Beta coefficient & Partial correlation & $\mathrm{P}$ \\
\hline \multicolumn{4}{|l|}{ Model 1- Dependent $\Delta \mathrm{CI}$} \\
\hline $\mathrm{DBic} \leq$ or $>$ than $38 \mathrm{mEq} / \mathrm{L}$ & -0.524 & -0.614 & 0.0001 \\
\hline K-Gap & 0.510 & 0.603 & 0.001 \\
\hline \multicolumn{4}{|l|}{ Model 2- Dependent $\triangle \mathrm{PVR}$} \\
\hline $\mathrm{DCa}<$ or $\geq$ than $1.5 \mathrm{mmol} / \mathrm{l}$ & 0.492 & 0.510 & 0.005 \\
\hline
\end{tabular}

DBic, dialysate bicarbonate; K-Gap, serum minus dialysate K; PTx, parathyroidectomy, DCa, dialysate calcium. Entire model $1: r=0.739$, adjusted $r^{2}=0.512, p=0.0001$. Other variables in this model: ultrafiltration rate and Na-Gap; Entire model 2: $r=0.605$, adjusted $\mathrm{r}^{2}=0.319, \mathrm{p}=0.002$. Other variables in this model: ultrafiltration rate.

\section{Bicarbonate dialysate content}

Metabolic acidosis is common in patients under maintenance HD and may have adverse consequences not only for bone metabolism $[11,12]$ but also on nitrogen balance, which might decrease skeletal muscle mass [13]. For such reasons, nephrologists struggle to reach KDIGO's goal of pre-HD serum bicarbonate concentration of $22 \mathrm{mEq} / \mathrm{l}$, [14] which can be obtained by increasing dialysate bicarbonate concentration [15]. Nevertheless, a recent prospective cohort study from DOPPS linked prolonged exposure to high dialysate bicarbonate levels to increased mortality [16]. Possible mechanisms are more frequent cardiac arrhythmias [17] and a greater propensity for intradialytic hypotensive episodes [7, 18], which could be related to higher intracellular shift of both calcium and potassium. In the present study, higher DBic was associated to a more pronounced decrease in post-HD $\mathrm{CI}$, regardless of pre-HD serum Bic concentration. Although we did not directly accessed intradialytic myocardial contraction/perfusion, one could hypothesize that higher DBic content might lead to MS and, therefore, to a worse cardiovascular outcome in this population. 


\section{Kidney \\ Blood Pressure Research}

Kidney Blood Press Res 2014;39:490-496

\begin{tabular}{l|l}
\hline DOI: $10.1159 / 000368459$ & $\begin{array}{l}\text { C 2 2014 S. Karger AG, Basel } \\
\text { www.karger.com/kbr }\end{array}$ \\
\hline Published onIIne: November 23, 2014 &
\end{tabular}

Silva et al.: Hemodynamic Behavior in Hemodialysis: Dialysate Bicarbonate and Potassium Content

Potassium dialysate content

Reducing DK content is an efficient measure for removing more potassium in a single dialysis session [19]. However, potassium's role on intradialytic hemodynamics remains elusive. In vitro studies have demonstrated increased myocardial contractility after acute exposure to potassium-deficient solutions [20, 21]. Conversely, chronic hypokalemia has an opposite effect, leading to inotropic response impairment after epinephrine or volume infusion [22]. Hypokalemia also affects vascular tonus, by inducing systemic vasoconstriction through a complex mechanism, which involves $\mathrm{Na}^{+}-\mathrm{K}^{+}$-ATPase inhibition, decreased uptake of norepinephrine into sympathetic nerve endings and increased calcium influx into vascular smooth muscle cell [23].

In this study, higher K-Gap (and, therefore, lower DK concentration) was associated to better post-HD CI. None of our patients were hypokalemic before HD. Our findings are consistent with increased myocardial contractility after acute reduction in serum potassium concentration, which are the same conclusions obtained by Brace et al. in a study performed with dogs treated with HD [24]. Such effect may be attributed to an ouabain-like effect of hypokalemia on sodium-potassium adenosine triphosphate of the myocytes [24]. Possibly, higher K-Gap promoted a more pronounced potassium removal, leading to a better myocardial performance at the end of HD session. Despite this favorable hemodynamic effect, it must be highlighted the risks associated to acute reductions in serum potassium on the development of arrhythmias and cardiac arrest during HD [25].

This study has some limitations: it was an observational study and the sample size was relatively small. We also did not directly measure effluent electrolyte concentrations in order to determine electrolyte balance during HD, which could explain some of our findings.

This study has several strengths: first of all, it describes how CI and PAR behave in response to ultrafiltration through a non-invasive assessment. Such behavior, although predictable, had never been described before through this methodology. Another strength was the demonstration that DBic and DK have independent impact over intradialytic hemodynamics. Previous studies only addressed the individual impact of DBic on hemodynamics. Additionally, as far as we are concerned, this is the first study to actually show the impact of acute hypokalemia on cardiac performance in humans under HD.

\section{Conclusion}

HD promotes a controlled hypovolemic state, with stroke volume and CI reduction, along with PAR increase in order to sustain BP. Dialysate content directly alters this hemodynamic balance: higher DBic and lower K-Gap lead to more profound post-HD CI reduction.

\section{Disclosure Statement}

The authors of this manuscript state that they do not have any conflict of interests and nothing to disclose.

\section{Acknowledgements}

We are grateful to all patients and nursing staff who collaborated to this study.

\section{References}

1 Block GA, Klassen PS, Lazarus JM, Ofsthun N, Lowrie EG, Chertow GM: Mineral metabolism, mortality, and morbidity in maintenance hemodialysis. J Am Soc Nephrol 2004;15:2208-2218. 


\section{Kidney \\ Blood Pressure Research}

Kidney Blood Press Res 2014;39:490-496

\begin{tabular}{l|l}
\hline DOI: $10.1159 / 000368459$ & (c) 2014 S. Karger AG, Basel
\end{tabular}

Publisnea onine: November 23, 2014

www.karger.com/kbr

Silva et al.: Hemodynamic Behavior in Hemodialysis: Dialysate Bicarbonate and Potassium Content

-2 Wizemann V, Wabel P, Chamney P, Zaluska W, Moissl U, Rode C, Malecka-Masalska T, Marcelli D: The mortality risk of overhydration in haemodialysis patients. Nephrol Dial Transplant 2009;24:1574-1579.

-3 Chazot C, Wabel P, Chamney P, Moissl U, Wieskotten S, Wizemann V: Importance of normohydration for the long-term survival of haemodialysis patients. Nephrol Dial Transplant 2012;27:2404-2410.

-4 McIntyre CW: Haemodialysis-induced myocardial stunning in chronic kidney disease - a new aspect of cardiovascular disease. Blood Purif 2010;29:105-110.

5 Gabutti L, Salvadé I, Lucchini B, Soldini D, Burnier M: Haemodynamic consequences of changing potassium concentrations in haemodialysis fluids: BMC Nephrol 2011;12:14.

6 Gabutti L, Lucchini B, Marone C, Alberio L, Burnier M: Citrate- vs. acetate-based dialysate in bicarbonate haemodialysis: consequences on haemodynamics, coagulation, acid-base status, and electrolytes: BMC Nephrol 2009;10:7.

7 Gabutti L, Bianchi G, Soldini D, Marone C, Burnier M: Haemodynamic consequences of changing bicarbonate and calcium concentrations in haemodialysis fluids. Nephrol Dial Transplant 2009;24:973981.

8 Locatelli F, Covic A, Chazot C, Leunissen K, Luño J, Yaqoob M: Optimal composition of the dialysate, with emphasis on its influence on blood pressure. Nephrol Dial Transplant 2004;19:785-796.

-9 Daugirdas JT: Simplified equations for monitoring Kt/V, PCRn, eKt/V, and ePCRn. Adv Ren Replace Ther 1995;2:295-304.

$>10$ Riddez L, Hahn RG, Brismar B, Strandberg A, Svensén C, Hedenstierna G: Central and regional hemodynamics during acute hypovolemia and volume substitution in volunteers. Crit Care Med 1997;25:635-640.

11 Kraut JA, Mishler DR, Singer FR, Goodman WG: The effects of metabolic acidosis on bone formation and bone resorption in the rat. Kidney Int 1986;30:694-700.

12 Gasser JA, Hulter HN, Imboden P, Krapf R: Effect of chronic metabolic acidosis on bone density and bone architecture in vivo in rats. Am J Physiol Renal Physiol 2014;306:F517-F524.

-13 Workeneh BT, Mitch WE: Review of muscle wasting associated with chronic kidney disease. Am J Clin Nutr 2010;91:1128S-1132S.

$\checkmark 14$ Kidney Disease: Improving Global Outcomes (KDIGO) CKD Work Group. KDIGO 2012 Clinical Practice Guideline for the Evaluation and Management of Chronic Kidney Disease. Kidney Int 2013;3:S1-150.

15 Oettinger CW, Oliver JC: Normalization of uremic acidosis in hemodialysis patients with a high bicarbonate dialysate. J Am Soc Nephrol 1993;3:1804-1807.

-16 Tentori F, Karaboyas A, Robinson BM, Morgenstern H, Zhang J, Sen A, Ikizler TA, Rayner H, Fissell RB, Vanholder R, Tomo T, Port FK: Association of dialysate bicarbonate concentration with mortality in the Dialysis Outcomes and Practice Patterns Study (DOPPS). Am J Kidney Dis 2013;62:738-746.

17 Heguilén RM, Sciurano C, Bellusci AD, Fried P, Mittelman G, Rosa Diez G, Bernasconi AR: The faster potassium-lowering effect of high dialysate bicarbonate concentrations in chronic haemodialysis patients. Nephrol Dial Transplant 2005;20:591-597.

18 Gabutti L, Ferrari N, Giudici G, Mombelli G, Marone C: Unexpected haemodynamic instability associated with standard bicarbonate haemodialysis. Nephrol Dial Transplant 2003;18:2369-2376.

19 Hou S, McElroy PA, Nootens J, Beach M: Safety and efficacy of low-potassium dialysate. Am J Kidney Dis 1989;13:137-143.

-20 Eisner DA, Lederer WJ: Inotropic and arrhythmogenic effects of potassium-depleted solutions on mammalian cardiac muscle. J Physiol 1979;294:255-277.

21 Ng YC, Hume JR, Akera T: Paradoxical positive inotropic effect of K+ in the rat heart. Am J Physiol 1987;252:H1005-H1015.

-22 Fitzovich DE, Hamaguchi M, Tull WB, Young DB: Chronic hypokalemia and the left ventricular responses to epinephrine and preload. J Am Coll Cardiol 1991;18:1105-1111.

23 Haddy FJ, Vanhoutte PM, Feletou M: Role of potassium in regulating blood flow and blood pressure. Am J Physiol Regul Integr Comp Physiol 2006;290:R546-R552.

24 Brace RA, Anderson DK, Chen WT, Scott JB, Haddy FJ: Local effects of hypokalemia on coronary resistance and myocardial contractile force. Am J Physiol 1974;227:590-597.

-25 Santoro A, Mancini E, London G, Mercadal L, Fessy H, Perrone B, Cagnoli L, Grandi E, Severi S, Cavalcanti S: Patients with complex arrhythmias during and after haemodialysis suffer from different regimens of potassium removal. Nephrol Dial Transplant 2008;23:1415-1421. 